\title{
artigo
}

\section{Risco biológico no cuidado de enfermagem junto aos clientes submetidos à hemodiálise: estudo sociopoético}

\author{
Biological risk in nursing care among clients submitted to hemodialysis: a sociopoetic study \\ Riesgo biológico en el cuidado de enfermería junto a los clientes sometidos a la hemodiálisis: estudio sociopoético
}

\begin{abstract}
RESUMO
Objetivo: analisar a dimensão imaginativa da enfermagem sobre o comportamento frente ao risco de acidentes com material biológico no cuidado aos clientes em hemodiálise. Método: descritivo, utilizou a sociopoética como referencial teórico metodológico. Após submissão Comitê de Ética em Pesquisa número CAAE 61649716.6.0000.5282 e aprovação Parecer Consubstanciado do CEP n. ${ }^{\circ}$ 1.858.402; os dados foram produzidos na Clínica Renal Vida Assistência Integral ao Renal, em seis oficinas sociopoéticas, com duração de duas horas, realizadas em abril de 2017 utilizando como técnica a Dinâmica do Corpo como Território Mínimo (DCTM). Resultados: foram delimitadas três categorias analíticas: - Risco inerente à prática; Como me proteger; e Necessário conhecer. Após a análise categorial temática, os dados foram descritos utilizando os estudos sociopoéticos: classificatório, transversal e filosófico. Conclusão: a equipe de enfermagem necessita de orientação sobre a importância das ações preventivas (autocuidado), a maioria possui conhecimento sobre risco biológico e autocuidado, mas nem sempre esse conhecimento se traduz em comportamento seguro.
\end{abstract}

DESCRITORES: Enfermagem; Diálise renal; Exposição a Agentes Biológicos; Estudo Sociopoético.

\section{ABSTRACT}

Objective: Analyze the imaginative dimension of the nursing professionals about the behavior regarding the risk of accidents with biological material in the care of the hemodialysis clients. Method: descriptive, used sociopoetics as theoretical methodological reference. After submitting Research Ethics Committee with the number CAAE 61649716.6.0000.5282 and approval by the Opinion Consubstantiated of the CEP No. 1.858.402; The data were produced in the Renal Vida Clinic Integral Assistance to the Renal, in six sociopoetic workshops, lasting two hours, held in April 2017 using the Dynamics of the Body as a Minimum Territory (DCTM) technique. Results: three analytical categories were delineated: - Risk inherent to the practice; How to protect myself; and Need to know. After the thematic categorical analysis, the data were described using sociopoetic studies: classificatory, transversal, and philosophical. Conclusion: The nursing team needs guidance on the importance of preventive actions (self-care), most of them have knowledge about biological risk and self-care, but this knowledge does not always translate into safe behavior.

DESCRIPTORS: Nursing; Renal Dialysis; Exposure at Biological Agents; Sociopoetic Study.

\section{RESUMEN}

Objetivo: analizar la dimensión imaginativa de los profesionales de la enfermería sobre el comportamiento frente al riesgo de los ácidos con material biológico sin cuidado junto a los clientes en hemodiálise. Método: descritivo, utilizou a sociopoética como referencial teórico metodológico. Después de la emisión Comitê de Ética en la búsqueda con número CAAE 61649716.6.0000.5282 y aprobación por Parecer Consubstanciado del número CEP: 1.858.402; Los datos son producidos en la Clínica Renal Vida Asistencia Integral al Renal, en seis oficinas sociológicas, con dos horas de duración, realizado en abril de 2017 utilizando la técnica de Dinámica de Corpo como Territorio Mínimo (DCTM). Resultados: se delimitou tres categorías analíticas: - Riesgo inherente a la práctica; Cómo protegerme; y necesito conocer. Después del análisis categorial temático, los datos fueron descritos utilizando los estudios sociopoéticos: clasificatorio, transversal y filosófico. Conclusión: el equipo de enfermería necesita orientación sobre la importancia de las acciones preventivas (autocuidado), la mayoría posee conocimiento sobre riesgo biológico y autocuidado, pero no siempre ese conocimiento se traduce en comportamiento seguro.

DESCRIPTORES: Enfermería; Diálisis Renal; Exposición a Agentes Biológico; Sociológico Estudio

RECEBIDO EM: 21/01/2020 APROVADO EM: 21/01/2020

\section{Leonor Coelho da Silva}

Enfermeira. Mestre. Doutoranda do Programa de Pós-Graduação em Enfermagem da UERJ. Capitão- Tenente (S) do Corpo de Saúde da Marinha do Brasil. https://orcid.org/0000-0001-5633-549X 


\section{Iraci dos Santos}

Enfermeira. Pós-Doutora. Professora Titular do Programa de Pós-Graduação em Enfermagem da Universidade do Estado do Rio de Janeiro, Brasil. https://orcid.org/0000-0002-1734-5561

\section{Adriana Loureiro da Cunha}

Enfermeira. Mestre. Doutoranda do Programa de Pós-Graduação em Enfermagem da Universidade do Estado do Rio de Janeiro, Brasil. https://orcid.org/0000-0002-6971-4357

\section{Leandro Andrade da Silva}

Enfermeiro. Pós-Doutor. Professor da Universidade Veiga de Almeida. Rio de Janeiro, Brasil. https://orcid.org/0000-00033213-5527

\section{Célia Pereira Caldas}

Enfermeira. Pós-Doutora. Professora titular da Universidade do Estado do Rio de Janeiro. Rio de Janeiro, Brasil. https://orcid. org/0000-0001-6903-1778

\section{Maria Gazel de Souza}

Enfermeira. Doutora. Enfermeira do Instituto Nacional do Câncer (INCA). Rio de Janeiro, Brasil. https://orcid.org/0000-00026247-9331

\section{Janaina Firmo da Silva}

Enfermeira. Especialista em Terapia Intensiva pela Universidade Federal do Rio de Janeiro. Capitão- Tenente (S) do Corpo de Saúde da Marinha do Brasil. https://orcid.org/0000-0002-6715-4878

\section{INTRODUÇÃO}

0 presente estudo refere-se a um recorte da dissertação de mestrado apresentada ao Programa de Pós-Graduação em Enfermagem da Universidade do Estado do Rio de Janeiro (PPGENF/UERJ), e insere-se na Linha de Pesquisa fundamentos filosóficos, teóricos e tecnológicos do cuidar em saúde e enfermagem, e no Grupo de Pesquisa Concepções teóricas para o cuidar em enfermagem e saúde - Conselho Nacional de Pesquisa (CNPq) e UERJ.

Aqui destaca-se que os rins são órgãos duplos, situados na porção posterior do abdome. Tem formato de feijão e medem cerca de $12 \times 6 \mathrm{~cm}$, pesando aproximadamente $150 \mathrm{~g}$ cada um, variando conforme a idade, peso e sexo. As principais funções dos rins são filtrar o sangue, participar no controle de líquidos do organismo e do equilíbrio hidroeletrolítico ${ }^{(1)}$.

Quando os rins se tornam incapazes de realizar suas funções, estabelece-se a insuficiência renal, que pode acontecer de forma abrupta, insuficiência renal aguda, ou lenta e progressivamente, insuficiência renal crônica; e dependendo do estágio e manifestações clínicas, torna-se necessário iniciar a terapia renal substitutiva (TRS).
O principal parâmetro de avaliação laboratorial, de indicação para o início TRS é o clearence de creatinina endógena, que deverá ter um valor igual ou inferior a 10 $\mathrm{ml} / \mathrm{min}$. Nos clientes com diabetes e nas crianças, a diálise pode ser iniciada com o valor de depuração da creatinina endógena igual ou menor que $15 \mathrm{ml} / \mathrm{min}^{(2)}$.

Clientes submetidos à hemodiálise (HD) com TRS estão mais susceptíveis a serem infectados pelos vírus HBV, HVC, e HIV. No entanto, para os profissionais de saúde, o risco de transmissão dos vírus HBV e HCV após acidente percutâneo são superiores ao $\mathrm{HIV}^{(3,4)}$.

Estima-se que a cada ano ocorram cerca de 66.000 casos de contaminação profissional pelo vírus da hepatite $\mathrm{B}, 16.000$ pelo da hepatite $\mathrm{C}$ e mais de 1000 casos pelo HIV em profissionais de saúde, após exposição ocupacional ${ }^{(5)}$.

No mundo, aproximadamente três milhões de profissionais da área de saúde sofrem injúrias com instrumentos ocupacionais a cada ano, com cerca de 2.000.000 exposições ao vírus da hepatite $\mathrm{B}(\mathrm{HBV})$ e 1.000 .000 ao vírus da hepatite $\mathrm{C}-\mathrm{HCV}^{(6)}$.

O maior índice de exposição ocupacional é a percutânea, seguida da cutaneomucosa. No entanto, a que expõe os profissionais ao maior risco de contaminação é a percutânea ${ }^{(6,7)}$.

O risco de exposição a estes vírus é proporcional ao manuseio de objetos perfuro cortantes e fluidos orgânicos, e o risco de aquisição após acidente percutâneo é de $1,8 \%$ para o $\mathrm{HCV}, 6-30 \%$ para o $\mathrm{HBV}$ e de 0,3 a $0,5 \%$ para o vírus da imunodeficiência humana- $\operatorname{HIV}^{(4,8,9)}$.

Os clientes submetidos à hemodiálise são considerados de alto risco para infecção pelo HCV. A prevalência de anticorpos anti-HCV é cerca de $25 \%$ superior nos indivíduos submetidos à $\mathrm{HD}$, já a prevalência de anticorpos HBsAg é similar ao da população em geral ${ }^{(10,11)}$.

No entanto, a persistência do genoma do HBV em clientes com o HBsAg negativo é uma possível fonte de transmissão do vírus, que representa risco tanto para clientes em HD quanto para profissionais ${ }^{(12)}$. Da mesma forma, uma pequena parcela de indivíduos infectados pelo $\mathrm{HCV}$, que possuem marcadores anti-HCV indetectáveis, constituem um problema diagnóstico e epidemiológico ${ }^{(13)}$.

Aproximadamente $0,9 \%$ de todos os casos confirmados de infecção pelo vírus da hepatite c no Brasil, tem como provável fonte a $\mathrm{HD}^{(4,15)}$, e a principal correlação é feita com a quebra das rotinas de precauções universais ${ }^{(11,16)}$. 


\section{artigo}

A equipe de enfermagem aparece como uma das profissões com maiores taxas de acidente envolvendo material biológico. No entanto, o número de profissionais expostos também é significativamente maior $^{(7,17)}$. Provavelmente pela necessidade de contato permanente com o cliente, nos diversos cenários da prática, e por este motivo o maior risco de se expor diretamente ao material biológico.

A sobrecarga de trabalho, falta de cursos específicos e indisponibilidade dos EPIs são fatores relacionados a não adesão às medidas de precaução universal, bem como, o maior tempo exercendo a profissão, porque tais profissionais receberam cursos de formação há mais tempo ${ }^{(4,9)}$. A confiança nas habilidades manuais e na rotina de trabalho favorece a banalização dos riscos existentes. Em contrapartida, a falta de conhecimento e a pouca experiência profissional pode dificultar a adesão às normas de precaução padrão ${ }^{(8,18)}$.

A Sociopoética trabalha com o imaginário, torna os sujeitos de pesquisa co-pesquisadores dos conhecimentos produzidos junto ao pesquisador institucional através da instituição do seu dispositivo analítico Grupo-Pesquisador (GP). Trabalha o corpo como fonte de conhecimento, explorando o potencial cognitivo das sensações, da emoção e da gestualidade para além da imaginação, da intuição e da razão/intelecto.

Nesse sentido, através de práticas artísticas de pesquisa, promove a criatividade no aprender, no conhecer, no pesquisar e no cuidar do ser humano; valoriza os conceitos e "confetos" (conceito + afeto, sentimentos) produzidos pelas culturas dominadas e de resistência e enfatiza as dimensões espiritual, humana e política da construção dos saberes ${ }^{(19,20)}$.

Neste artigo utilizou-se a Teoria e Filosofia Sociopoética para desvelar o imaginário dos profissionais de enfermagem que atuam em hemodiálise com o risco biológico ao qual estão expostos no seu fazer diário.

Entendendo que é fundamental a conscientização dos profissionais de saúde para a adoção de atitudes seguras no cuidado de pessoas em hemodiálise, buscou-se então, responder à questão orientadora: Como o risco biológico e as medidas de precaução padrão são percebidos pelos profissionais de enfermagem que atendem aos clientes em hemodiálise? Com o objetivo de analisar a dimensão imaginativa dos profissionais sobre o comportamento frente ao risco de acidentes com material biológico no cuidado junto com os clientes em hemodiálise.

\section{METODOLOGIA}

Os dados foram produzidos pelo Grupo-Pesquisador (GP) em uma clínica privada de assistência ao cliente renal, situada na Zona Norte do município do Rio de Janeiro-Brasil, no período de abril de 2017, durante 3 semanas. O GP instituído foi composto por 10 participantes (08 técnicos e 02 enfermeiros) que, após conhecerem a proposta do estudo, aceitaram participar voluntariamente.

Estudo realizado sobre o perfil sociodemográfico da equipe de enfermagem indica que esta é constituída $77 \%$ por técnicos e auxiliares e $23 \%$ por enfermeiros ${ }^{(22)}$.

A prevalência de técnicos de enfermagem também se justifica pela própria estrutura dos serviços de diálise, que estabelece que o número mínimo de técnicos de enfermagem é de um para quatro clientes por turno de diálise e de enfermeiros é de um para cada trinta e cinco ${ }^{(2)}$.

Foram realizadas seis oficinas sociopoéticas, com duração de duas horas, nas quais foi desenvolvido o pescurso (pesquisa + curso) cujo tema foi intitulado: "Biossegurança em Hemodiálise", no qual foram abordadas as peculiaridades relativas à assistência prestada no setor e os riscos aos quais os profissionais se expõem ao realizá-la. Depois do curso foi aplicada a técnica artística de pesquisa - Dinâmica do Corpo como Território Mínimo (DCTM) para a produção dos dados.

Sobre esta técnica de pesquisa, releva-se que, inicialmente foi realizada uma dinâmica de sensibilidade/relaxamento, para incentivar o imaginário. Posteriormente, foi discutido com os membros do GP o entendimento da palavra território para que fosse consensual a ideia de que nosso corpo possa ser concebido como território mínimo.

Utilizando essa técnica artística, com materiais de desenho à disposição, os participantes fizeram desenhos auto representativos, cujo objetivo, a priori, era fazê-los interpretar os desenhos, transparecendo a maneira como veem a possibilidade de se acidentar e adoecer durante sua prática profissional e utilizando o tema gerador: Como eu me cuido para prevenir acidente com material biológico? Como eu percebo o colega de trabalho utilizando os EPI?

Depois de expressarem seu imaginário a partir dos desenhos, os co-pesquisadores responderam às seguintes questões: Como eu me cuido para prevenir acidentes com material biológico? Quais são as minhas práticas profissionais que podem me expor ao risco de acidente com material biológico? Quais medidas preventivas eu desenvolvo? O que preciso conhecer para minimizar os riscos aos quais estou exposto? E como eu percebo o colega de trabalho utilizando os EPI?

Ressalta-se que aos participantes deste estudo foi apresentado um documento de Termo de Consentimento Livre e Esclarecido (TCLE), para ser assinado, conforme determinação da Resolução n. ${ }^{\circ} 466$ de 12 de dezembro de 2012, atendendo aos preceitos da ética, obrigatório para pesquisas envolvendo seres humanos. $\mathrm{O}$ projeto deste trabalho foi submetido previamente ao Comitê de Ética em Pesquisa (CEP) da Universidade do Estado do Rio de Janeiro (UERJ) com o número CAAE 61649716.6.0000 aprovado pelo Parecer Consubstanciado do CEP n. ${ }^{\circ} 1.858 .402$.

Os dados foram analisados e interpretados de acordo com a análise de conteúdo temático - categorial. Em seguida, os dados foram descritos utilizando os estudos sociopoéticos: classificatório, transversal e filosófico. O estudo classificatório destaca as oposições, dicotomias, alternativas, escolhas, existentes, no conjunto das produções do grupo-pesquisador; o estudo transversal destaca as ligações, ambiguidades e as convergências presentes nas produções do GP; e o estudo filosófico revela-se a partir das teorias escolhidas pelo facilitador da pesquisa e/ou dos membros do $\mathrm{GP}^{(23,24)}$. 


\section{RESULTADOS E DISCUSSÃO}

Foram delimitados 17 temas individuais, distribuídos em 3 categorias analíticas, a saber: Risco inerente à prática, composta por 8 temas; Como me proteger, composta por 4 temas; e Necessário conhecer, composta por 5 temas e apresentadas a seguir.

\section{Risco inerente à prática - estudo classificatório}

$\mathrm{Na}$ análise do imaginário do GP acerca das atividades inerentes à sua atividade profissional, e que podem expô-los ao risco de acidente envolvendo material biológico, podemos perceber duas distintas correntes de pensamento. Uma leva em consideração às atividades assistenciais propriamente ditas, realizadas em uma unidade de hemodiálise, conforme se observa nas falas a seguir:

"Durante a punção da fístula, manuseio de material ácido como Puristeril, o ambiente de trabalho como um todo, contato direto e indireto com o paciente".

"Curativo de hemostasia (FAV), punção FAV e retirada da agulha.

Realizando punção, manipulação de cateter, administrando medicação, instalando e devolvendo o paciente". (Falas do GP).

A outra, no entanto, considera não as atividades, mas o comportamento adotado pelo profissional frente ao risco, conforme se observa nas falas que se seguem:

"O não uso de EPI. O não cuidado. A falta de atenção".

"Não usando corretamente os EPI, não lavando as mãos corretamente". (Falas do GP).

Essa divergência de posições pode indicar que os profissionais reconhecem a necessidade do uso dos EPI, por isso relacionaram a não adesão como uma prática que podem deixá-los expostos ao risco, ou, em contrapartida, o fato de não citarem situações de risco pode sugerir que eles não conheçam efetivamente dentre as atividades que executam aquelas que os colocam em risco. Um dos relatos que cita a manipulação do ácido peracético como fator de risco biológico e não risco químico, pode corroborar esta hipótese.

$\mathrm{A}$ adesão aos EPI relaciona-se diretamente à percepção dos profissionais acerca do risco que cada procedimento impõe a sua saúde ocupacional, bem como da sua susceptibilidade a eles ${ }^{(25)}$.

Faz-se necessária a conscientização dos trabalhadores quanto à adoção de práticas seguras, bem como o reconhecimento dos fatores de risco ocupacional aos quais estão expostos ${ }^{(26)}$.

\section{Como me proteger- estudo transversal}

Nesta categoria, os temas individuais desvelados pelo GP apontaram para a conscientização da importância do uso do EPI adequado à atividade a ser realizada, da atenção para a realização dos procedimentos e da necessidade de manter-se atualizado.

"Uso correto dos EPI, lavagem das mãos e uso do álcool antisséptico".

"Uso máscara, capote, óculos, luva ou viseira quando necessário. Que quase sempre acontece".

"Me protegendo com os EPI, lavando as mãos e sempre fazendo com cuidado. Atenção, minimizando os riscos".

"Através das aulas de educação continuada. Tendo ciência que preciso me cuidar para bom andamento do serviço". (Falas do GP).

A adesão aos EPI é fundamental para uma prática segura nos serviços de saúde. Contudo, a segurança não se estabelece somente com o uso dos EPI, é necessário o conhecimento sobre sua utilização diante das diferentes situações ${ }^{(27)}$.

\section{Necessário conhecer - estudo trans- versal}

Emergiram nesta categoria temas individuais que reforçam a necessidade de se conhecer o risco ao qual se está exposto no fazer diário e reconhecer as diversas ações nas quais este risco encontra-se presente, realizando-as com cuidado e atenção. Destaca-se ainda o relato de necessidade de conhecer a forma correta de utilização do EPI.
Contudo, as falas que indicam a necessidade de conhecer o indivíduo que está sendo cuidado sugerem a intenção de prestar uma assistência humanizada, porém, em se falando de risco biológico, todas as normas de biossegurança devem ser adotadas universalmente, independente do conhecimento da condição sorológica do cliente.

\section{"Ter ciência de qual risco estou corren- do no momento e ter a máxima aten- ção ao lidar com os riscos biológicos". "Precisamos conhecer e ter acesso a todos os EPI". \\ "O paciente, o ambiente de traba- lho e toda a rotina que deve ser fei- ta e sempre fazer com atenção". "Atenção, cuidado, procurar conbecer o indivíduo que estou cuidando". "A importância da lavagem das mãos, do uso de EPI". (Falas do GP)}

O conhecimento influencia na prática cotidiana, e quanto mais aprofundado for, maior será o aprendizado adquirido, viabilizando decisões e atitudes coerentes ${ }^{(4)}$.

A avaliação do conhecimento acerca das medidas de precaução padrão dos profissionais de saúde é necessária, com o intuito de conscientizá-los quanto à importância da sua adesão ${ }^{(28)}$.

O sucesso do programa educativo está diretamente relacionado à participação e reconhecimento por parte dos trabalhadores e apoio das instituições ${ }^{(17) .}$

\section{Produções artísticas}

Utilizando a prática artística, foram produzidos 20 desenhos, 10 referentes à questão "Como eu me cuido para prevenir acidentes com material biológico?” e 10 à questão "Como eu percebo o colega de trabalho utilizando os EPI?”. Foram selecionadas duas produções apresentadas a seguir:

Os temas cuidado, EPI, lavagem das mãos desvelam que a co-pesquisadora 06 se preocupa com a sua segurança e com a segurança dos seus colegas de trabalho, sua auto representação totalmente paramentada sugere que ela está pronta para uma atuação segura e está feliz por isso, como demonstrado pelo seu sorriso. 
Figura 1. Cuido de mim do outro. Rio de Janeiro, RJ, Brasil, 2017.

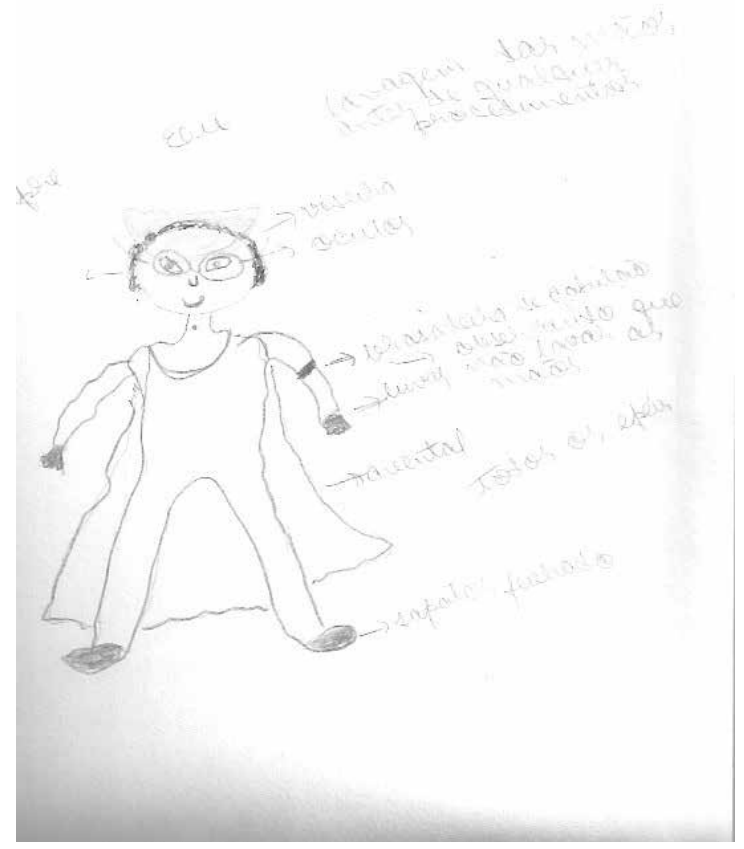

Figura 2. Acho que me protejo. Rio de Janeiro, RJ, Brasil, 2017.

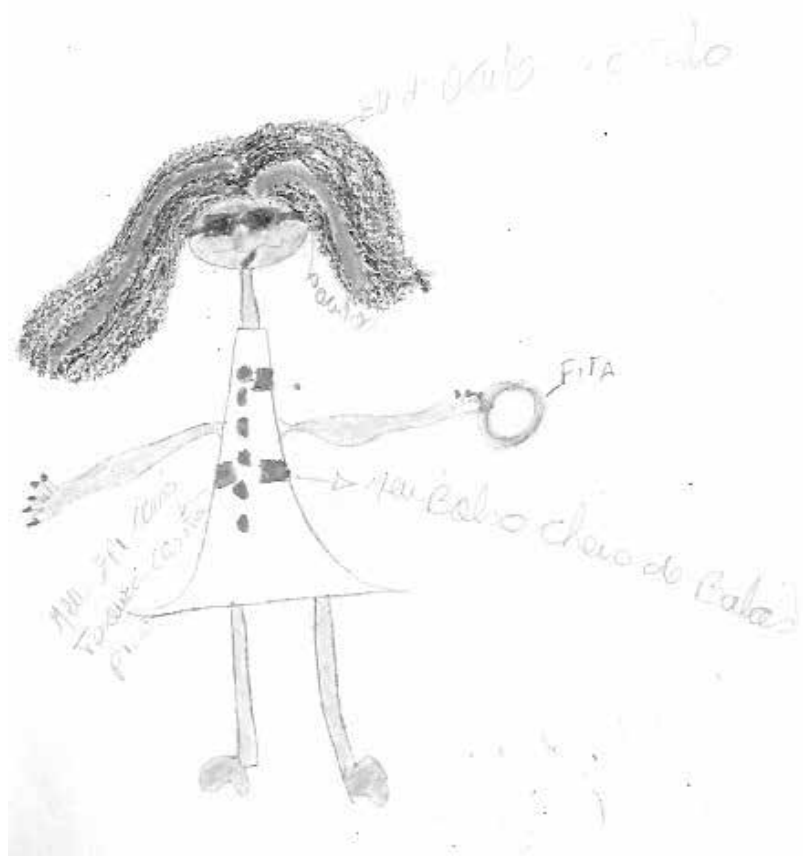

As influências interpessoais facilitariam aos indivíduos aderirem às condutas promotoras de saúde, pois estes tomariam conhecimento acerca das condutas, crenças e atitudes dos demais ${ }^{(29)}$.

Favorecendo, possivelmente, não só a adesão dos EPI, mais também a conscientização da importância da adesão e a preocupação com o outro.

Nesta produção emergiu o tema contradição, uma vez que, o desenho da co-pesquisadora 04 contradiz sua retórica, pois em sua produção ela se auto representa com os bolsos cheios de bala e na fala transmite a mensagem de usar corretamente os EPI, indicando preocupação com a biossegurança. De acordo com a Norma Regulamentadora 32 é proibido alimentar-se nos postos de trabalho onde exista o risco de acidente envolvendo material biológico ${ }^{(30)}$.

Destaca-se o risco de contaminação pelo $\mathrm{HBV}$, por exemplo, uma vez que, este vírus mantém-se estável em temperatura ambiente por até 7 dias em superfícies inanimadas ${ }^{(31)}$.

Para se atingir o ponto mais alto do desenvolvimento da razão, a autocrítica ou autoanálise, precisamos da ajuda do outro, uma vez que as nossas costas, nossa sombra, não podemos ver sem a ajuda do outro ${ }^{(21)}$.

\section{CONCLUSÃO}

O risco de exposição ocupacional ao sangue ou produtos sanguíneos potencialmente contaminados é uma realidade no cotidiano de trabalho dos profissionais de enfermagem que atuam nas unidades de hemodiálise.

Por isso, reconhecer este risco e as diversas situações nas quais ele está presente, bem como a utilização correta dos EPI, é fundamental para a prevenção de acidentes e para a minimização da exposição a agentes infecciosos, caso o acidente ocorra.

Foi possível constatar que a equipe de enfermagem necessita ser orientada sobre a importância das ações preventivas (autocuidado), que a maioria possui conhecimento sobre risco biológico e autocuidado, mas que nem sempre esse conhecimento se traduz em comportamento seguro. Evidenciando a necessidade de realização de cursos e treinamento acerca do tema. 


\section{REFERÊNCIAS}

1. Riella MC. Princípios de Nefrologia e Distúrbios Hidroeletrolíticos. 5 ed. Rio de Janeiro (RJ): Guanabara Koogan; 2010.

2. Ministério da Saúde (BR). Agência Nacional de Vigilância Sanitária. Resolução da Diretoria Colegiada - RDC n.o 154, de 15 de junho de 2004.

3. Mashragi F, Bernstein RS, Al-Mazroa M, Al-Tawfiq JA, Filemban S, Assiri A, et al. HIV Transmission at a Saudi Arabia Hemodialysis Unit, Clinical Infectious Diseases. 2014; 59(15):897-902.

4. Oliveira AC, Machado BCA, Gama CS, Damasceno QS. Avaliação das medidas de biossegurança na formação e atuação dos bombeiros militares. Rev. enferm. UERJ. 2012; 20(esp):701-07.

5. Souza-Borges FRF, Ribeiro LA, Oliveira LCM. Occupational exposures to body fluids and behaviors regarding their prevention and post-exposure among medical and nursing students at a brazilian public university. Rev. Inst. Med. trop. S. Paulo. 2014 Apr; 56(2):157-63.

6. Coppola N, De Pascalis S, Onorato L, Calò F, Sagnelli C, Sagnelli E. Hepatitis $B$ virus and hepatitis C virus infection in healthcare workers. World J Hepatol. 2016; 8(5): 273-81.

7. Almeida MCM, Canini SRMS, Reis RKa, Toffano SEM, Pereira FMV, Gir E. Seguimento clínico de profissionais e estudantes da área da saúde expostos a material biológico potencialmente contaminado. Rev. Enferm. USP. 2015 Abr; 49(2):259-64.

8. Faria AP, Souza JVC, Rabbi GMS, Favero JL, Prado TN. Hepatite B: conhecimento e medidas de biossegurança dos profissionais de saúde da Unidade de Emergência do Hospital Universitário Cassiano Antonio Moraes. 2014; 15(1):33-9.

9. Silva GS, Almeida AJ, Paula VS, Villar LM.Knowledge and utilization of standard precaution measures by health professionals. Esc. Anna Nery Rev. Enferm. 2012; 16(1):103-10.

10. Alashek WA, Mclntyre CW, Taal MW. Hepatitis B and C infection in haemodialysis patients in Libya: prevalence, incidence, and risk factors. BMC Infectious Diseases. 2012; 12 (265).

11. Cherchiglia ML, Giordano LFC, Machado EL, Gomes IC, Carmo RA, Acúrcio FA et al. Incidência de hepatite viral $C$ em pacientes em hemodiálise no Brasil entre 2000 e 2003. Cad. Saúde Pública. 2016; 32(8):e00167914.

12. Ramezani A, Aghasadeghi M R, Ahmadi F, Razeghi E, Eslamifar A, et al. Isolated Anti-HBc and Occult HBV Infection in Dialysis Patients, Nephro-Urol Mon. 2014; 7(1):e22674.

13. Kazmierczak J, Pawetezyk A, Cortes KC, Radkowski M. Seronegative hepatites C virus infection. Arch. Immunol. Ther. Exp. 2014; 62:145-51.

14. Ministério da Saúde, Departamento de DST, AIDS e Hepatites Virais, Secretaria de Vigilância em Saúde (BR). Estudo de prevalência de base populacional das infecções pelos vírus das hepatites $A, B$ e $C$ nas capitais do Brasil. Brasilia (DF): MS; $2010 .$.

15. Rosa DMS, Ribeiro IM. Fatores de risco para transmissão do vírus da hepatite C em pacientes submetidos à hemodiálise. CuidArte. 2013; 7(1):45-50.

16. Bianco A, Bova F, Nobile CGA, Pileggi C, Pavia M and the Collaborative Working Group. Healthcare workers and prevention of hepatitis $C$ virus transmission: exploring knowledge, attitudes, and evidence-based practices in hemodialysis units in Italy. BMC Infectious Diseases. 2013; 13(76).

17. Macchi Junior A, Quiaios A, Domingues JS, Ferreira A, Paixão S, Sá NL et al. Outcomes of accidents at work with exposure to biological agents. Human Grouth and Develp J 2014; 24(3):249-54.

18. Correa R, Souza N. Occupational risks faced by the nursing worker in a unit of hemodialysis. Rev. pesq. cuid. fundam. (Online). 2012 Sep 12; 4(4): 2755-764.

19. Santos I, Alves ACS, Silva FS, Penna LHG, Alvin NAT. Fundamentos filosóficos e teóricos para novas concepções do cuidar em enfermagem: contribuição da sociopoética. Rev. bras. enferm. (Online). 2010; 63(4):644-51.

20. Santos I dos, Silva LA, Gauthier J, Henri M, Guerra RGM. Contribuições da sociopoética à produção científica sobre cuidar em enfermagem: revisão integrativa de literatura. Rev. eletrônica enferm. 2013; 15(1): 243-52.

21. Gauthier J. Sociopoética - encontro entre arte, ciência e democracia na pesquisa em ciências humanas e sociais, enfermagem e educação. Rio de Janeiro (RJ): Editora Escola Anna Nery; 1999.

22. Machado MH. Características gerais da enfermagem: o perfil sócio demográfico. Enfermagem em Foco. 2015; 6(1):11-17.

23. Santos I Gauthier J, Figueiredo NMA, Petit SH (Orgs). Prática de Pesquisa nas Ciências Humanas e Sociais-Abordagem Sociopoética. São Paulo (SP): Atheneu; 2005.

24. Adad SJHC, Petit SH, Santos I, Gauthier J, organizadores. Tudo que não inventamos é falso. Fortaleza (CE): EdUECE; 2014.

25. Frota OP, Ferreira AM, Loureiro MDR, Cheade MFM, Reis MG. O uso de equipamento de proteção individual por profissionais de enfermagem na aspiração endotraqueal. Rev. enferm. UERJ. 2012; 20(esp.1):625-30.

26. Marziale MHP, Santos HEC, Cenzi CM, RochaFLR, Trovó MEM. Consequences of occupational exposure to biological material among workers from a university hospital. Esc. Anna Nery Rev. Enferm. 2014; 18(1):11-6.

27. Magagnini MAM, Honori VM, Takiguchi OMY, Silva PMG, Magagnini MM, Morand MS. Exposiç̧ão a fluidos biológicos e acidentes com graduandos de medicina e enfermagem. CuidArte Enfermagem. 2015 jan- jun; $9(1): 71-77$

28. Silva GS, Almeida AJ, Paula VS, Villar LM. Knowledge and utilization of standard precaution measures by health professionals. Esc. Anna Nery Rev. Enferm. 2012; 16(1):103-10.

29. Sakraida TJ. Nola Pender: Health Promotion Model. In: Tomey, A. M: Alligood, M. R. Nursing Theorist and their work. 8. ed. USA: Mosb; 2014. p. 452- 71.

30. Ministério do Trabalho e Emprego (BR). Normas Regulamentadoras. Norma Regulamentadora 32. Segurança e Saúde no Trabalho em Estabelecimentos de Saúde. Brasilia (DF): Ministério do Trabalho e Emprego; 2005.

31. Salgado TA. Acidentes com material biológico entre pessoas sem risco presumido. 2014. 90 f. Dissertação (Mestrado em Enfermagem). Goiânia: Universidade Federal de Goiás; 2014. 